\title{
The Profile of Antihypertensive Drug Prescriptions and Interactions at Pindad General Hospital
}

\author{
Yane S. Herliany, Siti R. Wahyuningsih \\ Bachelor Program of Pharmacy, Bumi Siliwangi Academy of Pharmacy, \\ Bandung, West Java, Indonesia
}

\begin{abstract}
Hypertension is a major problem in the world. World Health Organization (WHO) reported that 1.13 billion people in the world suffer from hypertension. This study aimed to determine the profile of antihypertensive prescriptions and drug interactions in outpatient installation at Pindad General Hospital, Bandung in January 2019. This study was non-experimental observational studies with retrospective data collection. There were 381 patients with hypertension (50.13\% female and $49.87 \%$ male). The most widely used antihypertensive drug is amlodipine (33.28\%) and calcium channel blocker drug (34.20\%). Moreover, we found $74.07 \%$ was moderate drug-drug interaction (DDI) with amlodipine and lisinopril as the most common cases $(21.08 \%)$. We concluded that $15.7 \%$ prescription contain antihypertensive drugs and moderate DDI occurred in the use of amlodipine and lisinopril. DDI should get more attention due to the clinical manifestations that may occur in patients.
\end{abstract}

Keywords : antihypertensive, prescription percentage, drug interaction

\section{Introduction}

Hypertension occurrs when the blood pressure in the arteries is persistently elevated. ${ }^{1}$ It currently becomes a major problem in the world because 1.13 billion people suffer from hypertension and only $36.8 \%$ of them take medicine. ${ }^{2}$ The number of people with hypertension in the world continues to increase every year due to poor lifestyle changes, such as smoking, obesity, alcohol consumption, and inadequate physical activity. $^{3}$

Along with the increase of hypertensive cases, the use of drugs is an important element in achieving the quality of health. When drug treatment is indicated, we need to choose which drug to be used first. The treatment should be decided by the proper evidence to reduce the risk of adverse drug reaction and drug interaction. ${ }^{3}$

Hypertension remains one of the leading causes of the burden of disease in several countries. Nearly one-half of all Indonesians aged over 40 years were hypertensive but only $7 \%$ had their blood pressure adequately controlled. ${ }^{4,5}$ Hypertensive cases in Indonesia reached $25.8 \%$ and the most commonly used drug is angiotensin-converting enzyme inhibitors (ACEI). ${ }^{6}$

Regarding to this finding, we aimed to determine antihypertensive prescription profile and drug interaction in outpatient installation at Pindad General Hospital.

Corresponding author: Siti R. Wahyuningsih, Bachelor Program of Pharmacy, Bumi Siliwangi Academy of Pharmacy, Bandung, West Java, Indonesia. Email: sitiratri@gmail.com

Received: 8 February 2020. Revised: 22 March 2020. Published: 1 April 2020. 


\section{Methods}

This research was a retrospective observational study that conducted at Pindad General Hospital. The data were shown in tables and figures. Inclusions criteria was the prescription with antihypertensive drugs that was daily taken at peak hours at the hospital. Whereas, exclusion criteria was the prescription without antihypertensive drugs.

\section{Samples}

Samples were prescriptions with antihypertensive drugs that entered to outpatient installation. The number of samples was calculated using the Slovin's formula to determine the minimum sample size (n), number of population (N) error tolerance limits (e). By calculation, we used 381 samples (Figure 1).

\section{Research Object}

Research object was data taken from prescription, including drug name, number of cases, and drug-drug (DDI) interaction. DDI was analysed by interactions checker on drugs.com and was accessed on http://www. drugs.com/drug_interactions.html.

\section{Results and Discussion}

There were 1255 prescriptions with antihypertensive drugs. Of these, 381 prescriptions ( $49.87 \%$ female and 50.13 male) were chosen to be identified. We categorized the number of patients by age. The result is shown in Table 1.

Hypertension attacks most in the aged over 65. The risk for suffering from hypertension in populations over 55 years who previously had normal blood pressure is $90 \%{ }^{7}$ Blood pressure tends to increase with age. This increase is mostly associated with structural changes, especially large artery stiffness or hardening of peripheral arteries causes decrease in elasticity and very similar to those resulting from the ageing process. ${ }^{8}$ Other pathophysiological shows decreased baroreceptor sensitivity, increased responsiveness to sympathetic nervous system stimuli, altered renal and sodium

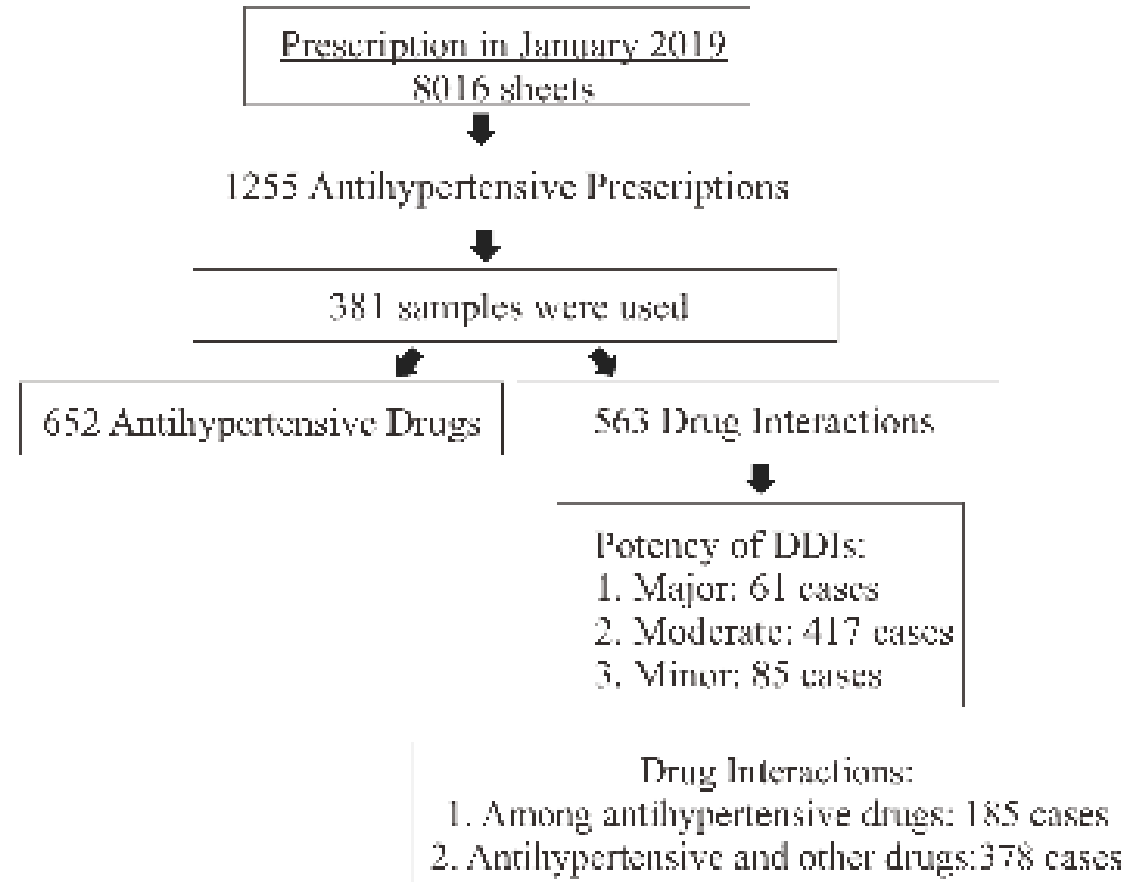

Figure 1. Flow of Calculation of Research Samples 
Table 1. Number of Patients by Age

\begin{tabular}{lcc}
\hline \multicolumn{1}{c}{ Age Range } & Number & Percentage (\%) \\
\hline Toddler (aged 0-5) & 0 & 0 \\
Children (aged 5-11) & 0 & 0 \\
Early Teenager (aged 12-16) & 0 & 0 \\
Late Teenager (aged 17-25) & 2 & 0.52 \\
Early Adult (aged 26-35) & 2 & 0.52 \\
Late Adult (aged 36-45) & 20 & 5.25 \\
Early Elderly (aged 46-55) & 81 & 21.26 \\
Late Elderly (aged 56-65) & 128 & 33.60 \\
Seniors (aged over 65) & 148 & 38.85 \\
\hline Total & 381 & 100 \\
\hline
\end{tabular}

Table 2. Antihypertensive Drugs Classification

\begin{tabular}{ccccc}
\hline Class of Drugs & Drugs & Frequency & Percentage & Total \\
\hline \multirow{2}{*}{ ACE-Inhibitor } & Captopril & 5 & 0.77 & \\
& Lisinopril & 90 & 13.80 & 15.34 \\
& Ramipril & 5 & 0.77 & \\
\hline \multirow{2}{*}{ Angiotensin Receptor } & Candesartan & 32 & 4.91 & \\
Blocker & Irbesartan & 16 & 2.45 & 8.44 \\
& Losartan & 3 & 0.46 & \\
& Telmisartan & 4 & 0.61 & \\
\hline Alpha Blocker & Tamsulosin & 34 & 5.21 & 5.21 \\
\hline Beta & Propanolol & 6 & 0.92 & 12.88 \\
Blocker & Bisoprolol & 78 & 11.96 & \\
\hline Calcium Channel & Amlodipine & 217 & 33.28 & 34.20 \\
Blocker & Diltiazem & 6 & 0.92 & \\
\hline Diuretic & Furosemide & 79 & 12.12 & 23.93 \\
& Spironolactone & 77 & 11.81 & \\
\hline & Total & 652 & 100.00 & 100.00 \\
\hline
\end{tabular}

metabolism and an altered renin-aldosterone relationship. ${ }^{9}$ Thus, we have to carefully pay attention about this case to improve the quality life of senior age.

\section{Drugs Prescription Profile}

Joint National Committee (JNC) recommends several antihypertensive drugs, including ACE inhibitors, angiotensin receptor blockers, beta blockers, calcium channels blockers, and diuretics. The prescription profile is shown in Table 2.
Appropriate antihypertensive drug therapy is important as the prevalence of hypertension has risen dramatically these days. In our study, antihypertensive drugs were used in 652 cases. The most commonly prescribed is amlodipine $(33.28 \%)$. Based on antihypertensive drug classes, the most commonly prescribed are calcium channel blockers $(34.20 \%)$ followed by diuretics and beta blockers, though diuretics are the first line of medication for the management of hypertension according to the JNC VII guideline. Diuretics were 
Table 3. Drug-Drug Interactions Among Antihypertensive Drugs

\begin{tabular}{lcc}
\hline Interactions & Frequency & Percentage (\%) \\
\hline Amlodipine - Lisinopril & 39 & 21.08 \\
Bisoprolol - Spironolactone & 29 & 15.68 \\
Lisinopril - Spironolactone & 27 & 14.59 \\
Amlodipine - Bisoprolol & 24 & 12.97 \\
Furosemide - Lisinopril & 19 & 10.27 \\
Bisoprolol - Furosemide & 18 & 9.73 \\
Candesartan - Spironolactone & 7 & 3.78 \\
Amlodipine - Captopril & 4 & 2.16 \\
Furosemide - Tamsulosin & 3 & 1.62 \\
Amplodipine - Ramipril & 2 & 1.08 \\
Bisoprolol - Diltiazem & 2 & 1.08 \\
Irbesartan - Spironolactone & 2 & 1.08 \\
Propanolol - Spironolactone & 2 & 1.08 \\
Captopril - Furosemide & 1 & 0.54 \\
Diltiazem - Lisinopril & 1 & 0.54 \\
Diltiazem - Tamsulosin & 1 & 0.54 \\
Furosemide - Propanolol & 1 & 0.54 \\
Furosemide - Rapimipril & 1 & 0.54 \\
Losartan - Spironolactone & 1 & 0.54 \\
Ramipril - Spironolactone & 1 & 0.54 \\
\hline Total & 185 & 100 \\
\hline
\end{tabular}

prescribed more often which is comparable to studies conducted in several countries including India and USA. ${ }^{10}$

\section{Drug-Drug Interactions}

There were 563 cases of DDI (Major: 61; Moderate: 417; and Minor: 85). Of these, 185 cases are drug pairs among the antihypertensive drugs (shown in table 3) and 378 cases are interaction between antihypertensive drugs with other drugs.

DDIs occur when the effect of one drug is altered by the co-administration of another drug. The alterations may result either from changes in the drug's effect independent of concentration (pharmacodynamic interaction) or from changes in the drug's concentration (pharmacokinetic interaction).
The common interacting drug pairs among the antihypertensive drugs were amlodipine/ lisinopril, bisoprolol/spironolactone, lisinopril/spironolactone, and amlodipine/ bisoprolol that similar to previous studies. ${ }^{11,12}$ Combination treatment using antihypertensive agents of two different classes are useful and promising in controlling blood pressure in patients with hypertension.

Among the data, amlodipine and lisinopril was the highest interaction occurred in hypertensive patient prescription. Calcium channel blockers and angiotensin converting enzyme (ACE) inhibitors may cause hypotension. These drugs are often safely used together, but monitoring of the systemic blood pressure is recommended. Captopril and furosemide is moderate DDI that can cause 
hypotension, that may relate to vasodilatation and relative intravascular volume depletion. ${ }^{13}$

Amlodipine and meloxicam were the common interaction between antihypertensive drugs and other drugs. This interaction was found in 93 cases $(10.5 \%)$ and had moderate potency. Combination of amlodipine and meloxicam may reduce the antihypertensive effect of amlodipine. Meloxicam will inhibit kidney prostaglandin synthesis that cause blood vessel dilation and increase blood pressure. ${ }^{14}$

\section{Conclusion}

Based on the results of this study it can be concluded that antihypertensive drugs have found in $15.7 \%$ from the total number of prescriptions. We used 381 prescriptions, Amlodipine (33.28\%) was the most common drug used. Moreover, we found $74.07 \%$ DDI with moderate potency. Adverse consequences ofDDI may result from either lower therapeutic effect or toxicity. DDI is usually preventable, when detected, pharmacist should determine appropriate prevention or management strategies.

\section{Acknowledgement}

Authors thank to all staff in Pindad General Hospital for assistance and help.

\section{Funding}

None.

\section{Conflict of Interest}

None declared

\section{References}

1. Wright JM, Musini VM. First-line drugs for hypertension. Cochrane Database System Reviews. 2009. doi:10.1002/14651858. CD001841.pub2

2. US Food and Drug Administration. Drug Interactions: What You Should Know.
Resour You . 2013;(May):1. https:// www.fda.gov/drugs/resourcesforyou/ ucm163354.htm.

3. Daskalopoulou SS, Rabi DM, Zarnke KB, et al. The 2015 Canadian Hypertension Education Program Recommendations for Blood Pressure Measurement, Diagnosis, Assessment of Risk, Prevention, and Treatment of Hypertension. Canadian Journal of Cardiology. 2015. doi:10.1016/j. cjca.2015.02.016

4. Rahajeng E, Tuminah S. Prevalence of Hypertension and Its Determinants in Indonesia. Journal of Indonesian Medical Association. 2009.

5. Hussain MA, Al Mamun A, Reid C, Huxley RR. Prevalence, awareness, treatment and control of hypertension in Indonesian adults aged $\geq 40$ years: Findings from the Indonesia Family Life Survey (IFLS). PLoS One. 2016. doi:10.1371/journal. pone.0160922

6. Fitriani. Profil Peresepan dan Evaluasi Interaksi Obat Antihipertensi pada Pasien Geriatri di Instalasi Rawat Inap Rumah Sakit Panti Rapih Yogyakarta Tahun 2005. Skripsi. 2007.

7. Chobanian A V., Bakris GL, Black HR, et al. Seventh report of the Joint National Committee on Prevention, Detection, Evaluation, and Treatment of High Blood Pressure. Hypertension. 2003. doi:10.1161/01.HYP.0000107251.49515. c2

8. Safar ME. Systolic hypertension in the elderly: Arterial wall mechanical properties and the renin-angiotensin-aldosterone system. Journal of Hypertension. 2005. doi:10.1097/01.hjh.0000163130.39149.fe

9. Weber MA, Neutel JM, Cheung DG. Hypertension in the aged: A pathophysiologic basis for treatment. American Journal of Cardiology. 1989. doi:10.1016/0002-9149(89)90112-4 
10. Gu Q, Paulose-Ram R, Dillon C, Burt $\mathrm{V}$. Antihypertensive medication use among US adults with hypertension. Circulation. 2006. doi:10.1161/ CIRCULATIONAHA.105.542290

11. Naidu MUR, Usha PR, Rao TRK, Shobha JC. Evaluation of amlodipine, lisinopril, and a combination in the treatment of essential hypertension. Postgraduate Medical Journal. 2000. doi:10.1136/ pmj.76.896.350

12. Cappuccio FP, Markandu ND, Singer DR MG. Amlodipine and lisinopril in combination for the treatment of essential hypertension: efficacy and predictors of response. Journal of Hypertension. $\quad 1993 ; 11(8): 839-847$. doi:10.1097/00004872-199308000-00011

13. Marquito $\mathrm{AB}$ atist., Fernandes $\mathrm{NM}$ da S, Colugnati FA ntoni. B, de Paula RB. Identifying potential drug interactions in chronic kidney disease patients. Journal of Brasilian Nefrology. 'orgão Of Soc Bras e Latino-Americana Nefrol. 2014. doi:10.5935/0101-2800.20140006

14. Stockley's drug interactions: a source book of interactions, their mechanisms, clinical importance and management. Choice Reviews Online. 2010. doi:10.5860/ choice.48-1222 